\title{
Effects of PEP-1-FK506BP on cyst formation in polycystic kidney disease
}

\author{
Hyo Sang Jo,"\#, Won Sik Eum ${ }^{1, \#, ~ E u n ~ Y o u n g ~ P a r k ~}{ }^{2}$, Je Young $\mathrm{Ko}^{2}$, Do Yeon Kim ${ }^{2}$, Dae Won Kim ${ }^{3}$, Min Jea Shin ${ }^{1}$, \\ Ora Son ${ }^{1}$, Su Bin Cho ${ }^{1}$, Jung Hwan Park ${ }^{1}$, Chi Hern Lee ${ }^{1}$, Eun Ji Yeo ${ }^{1}$, Hyeon Ji Yeo ${ }^{1}$, Yeon Joo Choi , Jong Kyu Youn ${ }^{1}$, \\ Sung-Woo Cho ${ }^{4}$, Jinseu Park ${ }^{1}$, Jong Hoon Park ${ }^{2, *}$ E Soo Young Choi ${ }^{1, *}$ \\ ${ }^{1}$ Department of Biomedical Science and Research Institute of Bioscience and Biotechnology, Hallym University, Chuncheon 24252, \\ ${ }^{2}$ Department of Biological Science, Sookmyung Women's University, Seoul 04310, ${ }^{3}$ Department of Biochemistry and Molecular Biology, \\ Research Institute of Oral Sciences, College of Dentistry, Gangneung-Wonju National University, Gangneung 25457, ${ }^{4}$ Department of \\ Biochemistry and Molecular Biology, University of Ulsan College of Medicine, Seoul 05505, Korea
}

Polycystic kidney disease (PKD) is one of the most common inherited disorders, involving progressive cyst formation in the kidney that leads to renal failure. FK506 binding protein 12 (FK506BP) is an immunophilin protein that performs multiple functions, including regulation of cell signaling pathways and survival. In this study, we determined the roles of PEP-1FK506BP on cell proliferation and cyst formation in PKD cells. Purified PEP-1-FK506BP transduced into PKD cells markedly inhibited cell proliferation. Also, PEP-1-FK506BP drastically inhibited the expression levels of p-Akt, p-p70S6K, p-mTOR, and p-ERK in PKD cells. In a 3D-culture system, PEP-1FK506BP significantly reduced cyst formation. Furthermore, the combined effects of rapamycin and PEP-1-FK506BP on cyst formation were markedly higher than the effects of individual treatments. These results suggest that PEP-1-FK506BP delayed cyst formation and could be a new therapeutic strategy for renal cyst formation in PKD. [BMB Reports 2017; 50(9): 460-465]

\section{INTRODUCTION}

Polycystic kidney disease (PKD), one of the most common genetic kidney disorders, is characterized by progressive cyst formation and development of fluid-filled cysts in the kidney,

*Corresponding authors. Soo Young Choi, Tel: +82-33-248-2112; Fax: +82-33-241-1463; E-mail: sychoi@hallym.ac.kr; Jong Hoon Park, Tel: +82-2-710-9414; Fax: +82-2-2077-7322; E-mail: parkjh@ sookmyng.ac.kr

${ }^{\#}$ These authors contributed equally to this work.

https://doi.org/10.5483/BMBRep.2017.50.9.090

Received 30 May 2017, Revised 20 June 2017, Accepted 20 July 2017

Keywords: Cyst formation, PEP-1-FK506BP, Polycystic kidney diseases, Protein therapy, 3D culture ultimately leading to end-stage kidney disease (1-3). Two major PKD subtypes have been identified i.e, autosomal dominant PKD (ADPKD) and autosomal recessive PKD (ARPKD). ADPKD is the most highly prevalent inherited disorder caused by either PKD1 or PKD2 gene mutations and affects one in 1000 adults. ARPKD is caused by a PKHD1 gene mutation and affects one in 20,000 children (4-6). Although the exact mechanisms of cyst formation in PKD are not clear yet, recent studies have demonstrated that various factors, including cytokines, growth factors, extracellular matrix (ECM) components and matrix metalloproteinases (MMPs) contribute significantly to cell proliferation and cyst formation in human patients and animal models of PKD (4, 7-12).

It has been shown that mammalian target of rapamycin (mTOR) and Akt signaling play important roles in the pathophysiology of PKD via increased mTOR activation in both human PKD and animal models. The collective evidence suggests that the common feature of PKD is mTOR activation. Therefore, the regulation of mTOR activation is important in the development of therapeutic strategies for PKD treatment (13-16). In addition, other studies have shown that phosphorylation of PI3K, Akt, mTOR, and mitogen-activated protein kinase (MAPK) pathways markedly inhibited cancer cell proliferation and growth, suggesting that understanding of these mechanisms may contribute to the development of drugs for the inhibition of cell proliferation and growth (17-20).

FK506 binding protein 12 (FK506BP), one of the FKBP family of proteins, is a major immunophilin protein and demonstrates peptidylprolyl cis/trans isomerase (PPlase) activity (21). FK506BP performs multiple functions in cells e.g., protein folding, regulation of calcium-dependent phosphatase calcineurin (CaN) and transforming growth factor- $\beta$ (TGF- $\beta$ ) $(21,22)$. In addition, other studies have shown that FK506BP has protective effects in neurodegenerative processes and apoptotic neuronal cell death in diseases, including Parkinson's diseases, suggesting that FKBP plays important roles in cell survival and may provide a new therapeutic target for neurodegenerative diseases (23-29). The complex of FK506BP

ISSN: 1976-670X (electronic edition)

Copyright (c) 2017 by the The Korean Society for Biochemistry and Molecular Biology

(c) This is an open-access article distributed under the terms of the Creative Commons Attribution Non-Commercial License (http://creativecommons.org/licenses/by-nc/4.0) which permits unrestricted non-commercial use, distribution, and reproduction in any medium, provided the original work is properly cited. 
and rapamycin plays a role as inhibitor of mTORC1 activation which, in turn, leads to suppression of cell growth via regulation of cell signaling in various cells, including cancer cells (30-32).

Although FK506BP has multiple potent therapeutic functions, it is limited for therapeutic application since it is very low delivery efficiency. Therefore, we fused FK506BP and a PEP-1 peptide (one of the various protein transduction domains [PTDs]). This fusion protein was able to cross membranes such as the blood-brain barrier (BBB) without any toxic effects $(33,34)$. In a previous study, we have shown that PEP-1-FK506BP inhibited atopic dermatitis (AD) and eye diseases $(35,36)$. Although FK506BP is known to perform multiple functions in cellular processes, the effects of FK506BP in PKD remains unclear. Therefore, we investigated the effect of PEP-1-FK506BP on cell proliferation and cyst formation in PKD. Our results showed that PEP-1-FK506BP markedly inhibited cell proliferation and cyst formation in PKD cells.

\section{RESULTS AND DISCUSSION}

PEP-1-FK506BP transduction into WT9-7 PKD epithelial cells PKD, a well-known genetically inherited disorder, leads to the

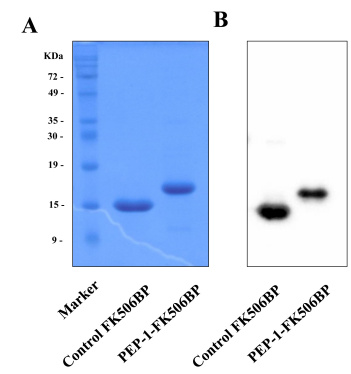

C

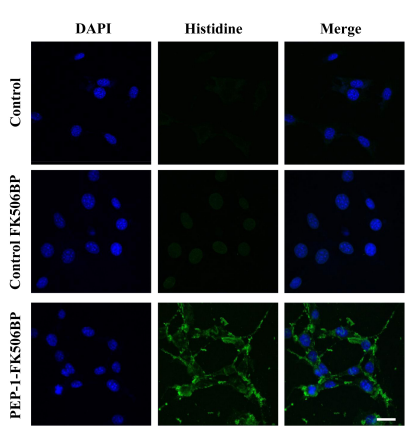

Fig. 1. Purification and transduction of PEP-1-FK506BP into WT9-7 cells. Purified PEP-1-FK506BP and control FK506BP were analyzed by $15 \%$ SDS-PAGE (A) and subjected to Western blot analysis with an anti-histidine antibody (B). Transduction of PEP-1-FK506BP into WT9-7 cells. The cells were treated with PEP-1-FK506BP (5 $\mu \mathrm{M})$ proteins for $2 \mathrm{~h}$ and observed by confocal microscopy (C). Scale bar $=20 \mu \mathrm{m}$. formation of cysts in the kidney and eventually causes renal failure (1-3). However, there no specific anti-PKD agent has been developed to prevent or treat renal failure. Although FK506BP is associated with survival processes in cells $(21,22)$, the roles of FK506BP in PKD are not clear. In this study, we investigated the roles of PEP-1-FK506BP on cyst formation. PEP-1-FK506BP was purified as described in previous reports $(35,36)$. As shown in Fig. 1A and 1B, we used SDS-PAGE and Western blotting to identify and confirm the purities of PEP-1-FK506BP and the control FK506BP. We also used immunofluorescence staining (Histidine and DAPI) to show that PEP-1-FK506BP could be transduced into WT9-7 cells (Fig. 1C). Other studies have shown that various PEP-1 fusion proteins could be transduced into cells (37-39).
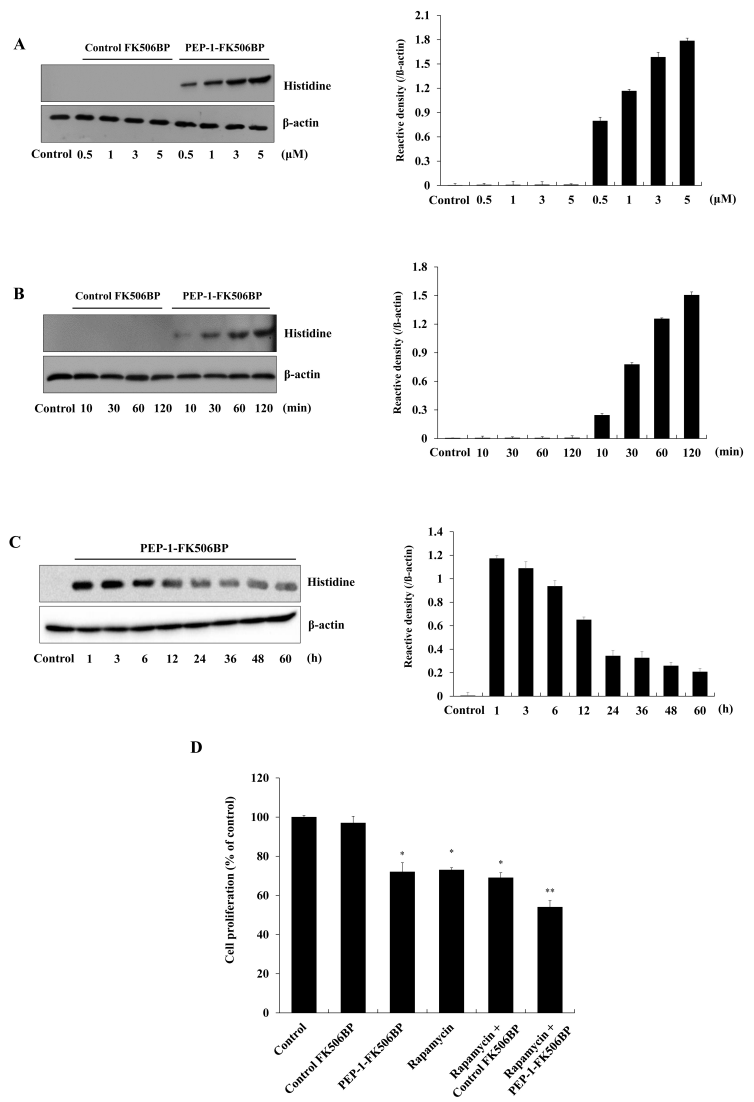

Fig. 2. Transduction efficiency of PEP-1-FK506BP. 0.5-5 $\mu \mathrm{M}$ of PEP-1-FK506BP proteins was added to WT9-7 cell culture media for $2 \mathrm{~h}(\mathrm{~A})$ or PEP-1-FK506BP $(5 \mu \mathrm{M})$ proteins was added to the cell culture media for 10-120 min (B). The stability of PEP-1FK506BP. WT9-7 cells were treated with $5 \mu \mathrm{M}$ PEP-1-FK506BP and incubated for 1-60 h, analyzed by Western blotting, and band intensity was measured by densitometry (C). WT9-7 cells were treated with PEP-1-FK506BP $(5 \mu \mathrm{M})$ and rapamycin $(0.5 \mathrm{nM})$ for $24 \mathrm{~h}$. Cell proliferation was determined (D). ${ }^{* P}<0.05$ and $* * P<0.01$, compared with control cells. 
Next, we used Western blots to analyze the extent to which PEP-1-FK506BP could be transduced into WT9-7 cells. The cells were treated with various concentrations of PEP-1FK506BP $(0.5-5 \mu \mathrm{M})$ for $2 \mathrm{~h}$ or with PEP-1-FK506BP $(5 \mu \mathrm{M})$ for different durations (10-120 min). Time- and dose-dependent transductions of PEP-1-FK506BP transduced into WT9-7 cells are shown in Fig. 2A and 2B. However, control FK506BP without a PEP-1 peptide did not transduce into cells. Furthermore, we determined the intracellular stability of PEP-1-FK506BP in WT9-7 cells (Fig. 2C). PEP-1-FK506BP was stable for $12 \mathrm{~h}$ in cells. Consistent with previous studies, these results indicated that PEP-1-FK506BP could be efficiently transduced into WT9-7 cells where it remained stable $(35,36)$.

\section{Effects of PEP-1-FK506BP on WT9-7 cell proliferation}

Several studies have demonstrated that various factors, including cytokines and growth factors, play a role in the proliferation of cystic epithelial cells - one of the key features of PKD $(4,7,8)$. Thus, we investigated the effects of PEP-1FK506BP on WT9-7 cell proliferation using a MTT cell viability assay. As shown in Fig. 2D, PEP-1-FK506BP markedly inhibited WT9-7 cell proliferation when compared to control cells. Combined treated with rapamycin and PEP-1-FK506BP further inhibited cell proliferation relative to the inhibition of proliferation by only rapamycin or PEP-1-FK506BP. Rapamycin is a known inhibitor of mTOR signaling, which inhibits cellular growth, proliferation, and cytogenesis in PKD. In addition, preclinical studies have shown that inhibition of mTOR activation in an animal model of PKD reduced PKD, suggesting that mTOR inhibition will effectively slow cyst proliferation (14, 40-43). In agreement with other studies, we have shown that PEP-1-FK506BP and rapamycin significantly inhibited WT9-7 cell proliferation.

In addition, we examined the effect of PEP-1-FK506BP on the signaling pathways regulating cellular proliferation in WT9-7 cells. Several studies have shown that inhibition of signaling involved in cellular proliferation, including $\mathrm{mTOR}$, is attenuated in PKD patients. Because inhibition of the mTOR signaling pathway is associated with therapeutic benefits in PKD animal models, the results suggest that inhibition or regulation of cell proliferation signals is one of the key therapeutic targets for PKD $(14,16,44,45)$. As shown in Fig. 3A-3B, phosphorylation patterns of Akt, p70S6K and mTOR were significantly reduced by PEP-1-FK506BP. In contrast, rapamycin increased the phosphorylation of extracellular signal-regulated kinase (ERK) (Fig. 3C). However, combined treatment with PEP-1-FK506BP and rapamycin markedly reduced the phosphorylation patterns of Akt, p70S6K, mTOR and ERK compared with the same result obtained following treatment with only PEP-1-FK506BP or rapamycin in WT9-7 cells.

It is well known that mTOR is involved in different signaling pathways, including PI3K/Akt, NF- $\mathrm{KB}$, and protein synthesis. Additionally, the mTOR signaling pathway plays a crucial role
A
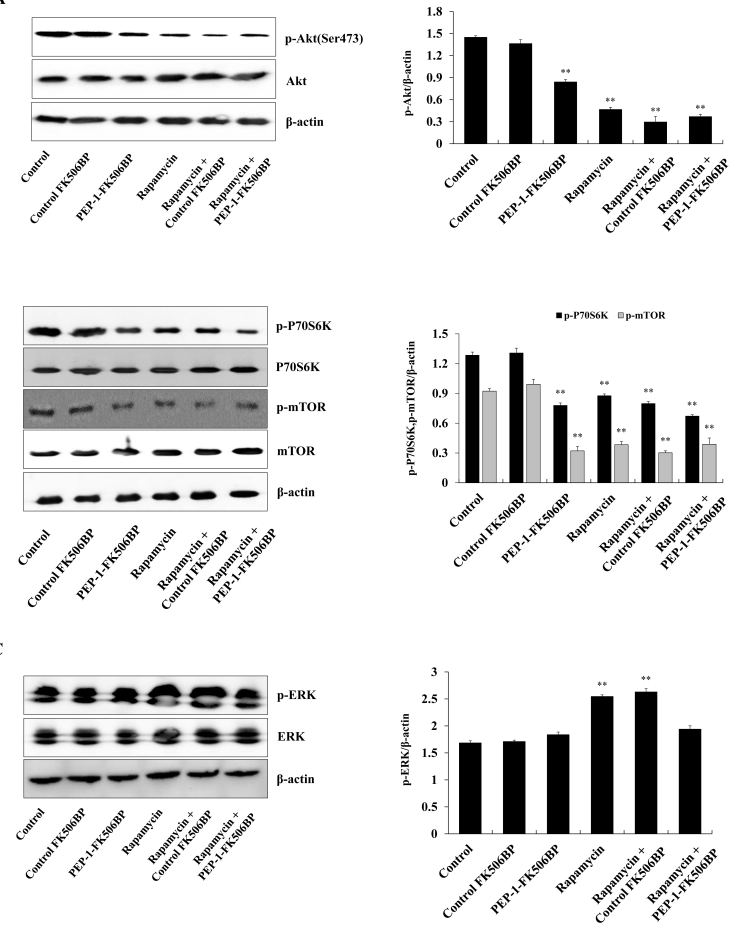

Fig. 3. Effects of PEP-1-FK506BP on cell proliferation. WT9-7 cells were treated with PEP-1-FK506BP $(5 \mu \mathrm{M})$ and rapamycin $(0.5$ $\mathrm{nM})$. After $24 \mathrm{~h}$, the expression levels of Akt (A), p70S6K and mTOR (B), and ERK (C) were determined by Western blotting using the indicated specific antibodies. $* * P<0.01$, compared with control cells.

in the regulation of cell proliferation, survival, and growth by phosphorylation of ribosomal p70S6 kinase (p70S6K). The latter enzyme is downstream of mTOR in eukaryotic cells (13-16, 43-45). ERK, one of the MAPKs, is associated with cell proliferation in cells (17-20). In addition, Chang et al. demonstrated that PKD cellular proliferation is associated with the ERK signaling pathway (46). Consistent with these results, we demonstrated that PEP-1-FK506BP inhibited cell proliferation via regulation of associated signaling pathways, including Akt, p70S6K, and ERK.

Effects of PEP-1-FK506BP on cyst formation in 3D culture Several studies in human PKD patients and animal PKD models have demonstrated that overexpression of collagen is highly associated with PKD and the progression of cystic diseases $(11,47-49)$. Thus, we examined the effect of PEP-1FK506BP on cyst formation in Madin-Darby canine kidney epithelial (MDCK) cells using three-dimensional collagen I cyst culture systems. The formation of cysts was markedly decreased compared to the same process in the control following treatment of cells with PEP-1-FK506BP (Fig. 4). The formation of cysts was also significantly decreased in the 

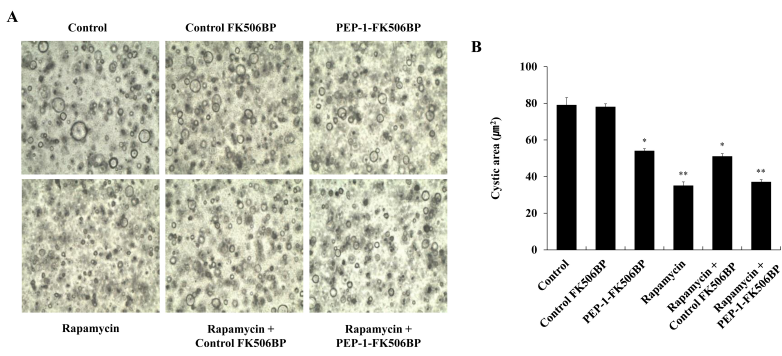

Fig. 4. Effects of PEP-1-FK506BP against cyst formation. MDCK cells were treated with forskolin to stimulate cyst formation. After PEP-1-FK506BP $(5 \mu \mathrm{M})$ and rapamycin $(0.5 \mathrm{nM})$ were added to the culture media, cyst formation was observed via a microscope (A) and cyst size was measured (B). $* \mathrm{P}<0.05$ and $* * \mathrm{P}<$ 0.01, compared with control cells.

rapamycin-treated cells. The cells treated with both PEP-1FK506BP and rapamycin, showed similar levels of cyst formation compared to treatment with only rapamycin.

Rapamycin is clinically used as an immunosuppressant and considered to be a key therapeutic drug for the treatment of PKD (45). However, several studies demonstrated that combinations of rapamycin with other drugs have synergistic effects, whereas rapamycin alone shows insufficient therapeutic effects in PKD $(13,15,42,50)$. Although further study is needed to understand the precise therapeutically beneficial molecular mechanism, these results indicate that a combination of PEP-1-FK506BP with rapamycin plays a critical role in the inhibition of cyst formation in PKD. Since various clinical trials in PKD have failed at the present time, our discovery of an effective therapeutic target for this disease bodes well for future applications.

In conclusion, we showed that PEP-1-FK506BP could be transduced into PKD cells and inhibited cell proliferation and cyst formation. These results suggest that PEP-1-FK506BP plays crucial roles in PKD and may be a new potential target molecule for PKD.

\section{MATERIALS AND METHODS}

\section{Materials}

WT9-7 cells, originally derived from a human autosomal dominant polycystic kidney disease (ADPKD) kidneys, and Madin-Darby canine kidney epithelial (MDCK) cells, a normal kidney epithelial cell line from Canis familiaris, were obtained from the American Type Culture Collection (ATCC; Manassas, VA, USA). Histidine and $\beta$-actin antibodies were obtained from Santa Cruz Biotechnology (Santa Cruz, CA, USA). Akt, p-Akt, p70S6K, p-p70S6K, mTOR, p-mTOR, ERK, p-EKR, and peroxidase-conjugated secondary antibodies were obtained from Cell Signaling Technology (Beverly, MA, USA). Rapamycin was obtained from Sigma-Aldrich (St. Louis, MO, USA). Unless otherwise stated, all other agents were of the highest grade available.

\section{Cell culture}

WT9-7 and MDCK cell lines were obtained from the American Type Culture Collection (ATCC, Manassas, VA, USA). WT9-7 cells cultured in DMEM containing $10 \%$ fetal bovine serum (FBS) with antibiotics $(100 \mu \mathrm{g} / \mathrm{ml}$ streptomycin, $100 \mathrm{U} / \mathrm{ml}$ penicillin). MDCK cells were cultured in DMEM/F12 with $10 \%$ FBS and antibiotics. Both cells were maintained at $37^{\circ} \mathrm{C}$ in a humidified chamber $\left(5 \% \mathrm{CO}_{2}\right.$ and $95 \%$ air).

\section{Purification and transduction of PEP-1-FK506BP into WT9-7 cells}

PEP-1-FK506BP and control FK506BP proteins were purified as previously described (35) and quantitated by the Bradford assay (51).

For transduction of PEP-1-FK506BP, WT9-7 cells were treated with 0.5-5 $\mu \mathrm{M}$ PEP-1-FK506BP for $2 \mathrm{~h}$ or treated with 5 $\mu \mathrm{M}$ PEP-1-FK506BP for 10-120 min. Cells were treated with 5 $\mu \mathrm{M}$ PEP-1-FK506BP for $2 \mathrm{~h}$ to determine the intracellular stability of transduced PEP-1-FK506BP. Cells were then washed and further incubated for 1-60 h.

\section{Confocal microscopy analysis}

We performed a previously described double-staining procedure using Alexa Fluor-488 and DAPI to confirm the transduction of PEP-1-FK506BP into WT9-7 cells $(35,52,53)$. Briefly, the cells were treated with PEP-1-FK506BP for $2 \mathrm{~h}$, washed, fixed, and blocked. Then the cells were incubated with a His-primary antibody and Alexa Fluor-488 secondary antibody in the dark. Nuclei were stained for 2 min with 1 $\mu \mathrm{g} / \mathrm{ml}$ DAPI. Fluorescence in the cells was observed using a FV-300 confocal microscope (Olympus, Tokyo, Japan).

\section{Western blot analysis}

Proteins were separated with 15\% SDS-PAGE and transferred onto a nitrocellulose membrane. The membrane was blocked with $5 \%$ nonfat dry milk in TBST buffer $(25 \mathrm{mM}$ Tris- $\mathrm{HCl}, 140$ $\mathrm{mM} \mathrm{NaCl}, 0.1 \%$ Tween 20, pH 7.5) for $1 \mathrm{~h}$ and incubated with the indicated primary and horseradish peroxidaseconjugated secondary antibody. The protein bands were detected using ECL reagents (Amersham, Franklin Lakes, NJ, USA) and the band density was quantified using Image J software $(52,53)$.

\section{Cell proliferation assay}

Briefly, cell proliferation was assessed using a previously described MTT viability assay $(12,52)$. Cells $\left(1 \times 10^{4}\right)$ were seeded into 24-well plates and incubated for $12 \mathrm{~h}$. Cells grown in appropriate culture media were treated with PEP-1-FK506BP $(5 \mu \mathrm{M})$ and rapamycin $(0.5 \mathrm{nM})$ for $2 \mathrm{~h}$ and $24 \mathrm{~h}$, respectively. The cells were then treated with MTT solution and the optical density was measured using a microplate reader. Cell proliferation was defined as the percentage of untreated 
control cells.

\section{Three-dimensional cell culture}

Three-dimensional cell culture was performed as described previously (12). MDCK cells were suspended in $10 \times$ DMEM and $10 \times$ reconstitution buffer $\left(2.2 \% \mathrm{NaHCO}_{3}\right.$ and $4.8 \%$ HEPES). Collagen rat tail type I was added to the suspended cells and neutralized with 10N NaOH. PEP-1-FK506BP (5 $\mu \mathrm{M})$ and rapamycin $(0.5 \mathrm{nM})$ were added to the culture media of forskolin-treated cells (forskolin induces cystogenesis). Cyst formation was then observed via a microscope. Cyst volumes were measured and compared with one another using Adobe Photoshop CS3 software.

\section{Statistical analysis}

Data were expressed as the means \pm SD from three experiments. Differences among means were analyzed using one-way ANOVA and student's t-tests. Significant differences were expressed as $\mathrm{P}<0.05$ and $\mathrm{P}<0.01$.

\section{ACKNOWLEDGEMENTS}

This work was supported by a Priority Research Centers Program grant (2009-0093812), Mid-Career Researcher Program grant (2016R1A2B4008356) and Bio \& Medical Technology Development Program grant (2015M3A9B6027555) through the National Research Foundation of Korea funded by the Ministry of Education, and Ministry of Science, ICT \& Future Planning in the Republic Korea, and it was supported by the Hallym University Research Fund (HRF-201607-009).

\section{CONFLICTS OF INTEREST}

The authors have no conflicting financial interests.

\section{REFERENCES}

1. Wilson PD and Goilav B (2007) Cystic disease of the kidney. Annu Rev Patho 2, 341-368

2. Pei Y and Watnick T (2010) Diagnosis and screening of autosomal dominant polycystic kidney disease. Adv Chronic Kidney Dis 17, 140-152

3. Harris PC and Torres VE (2009) Polycystic kidney disease. Annu Rev Med 60, 321-337

4. Ye M, Grant M, Sharma M et al (1992) Cyst fluid from human autosomal dominant polycystic kidneys promotes cyst formation and expansion by renal epithelial cells in vitro. J Am Soc Nephrol 3, 984-994

5. Yoder BK, Mulroy S, Eustace H, Boucher $\mathrm{C}$ and Sandford R (2006) Molecular pathogenesis of autosomal dominant polycystic kidney disease. Expert Rev Mol Med 8, 1-22

6. Al-Bhalal L and Akhtar M (2008) Molecular basis of autosomal recessive polycystic kidney disease (ARPKD). Adv Anat Patho 15, 54-58

7. Gardner KD Jr, Burnside JS, Elzinga LW and Locksley RM (1991) Cytokines in fluids from polycystic kidneys. Kidney
Int 39, 718-724

8. Park EY, Woo YM and Park JH (2011) Polycystic kidney disease and therapeutic approaches. BMB Rep 44, 359-368

9. Harada $\mathrm{H}$, Furuya $M$, Ishikura $\mathrm{H}$ et al (2002) Expression of matrix metallo proteinase in the fluids of renal cystic lesions. J Urol 168, 19-22

10. Liu B, Li C, Liu Z, Dai Z and Tao Y (2012) Increasing extracellular matrix collagen level and MMP activity induces cyst development in polycystic kidney disease. BMC Nephrol 13, 109

11. Candiano G, Gusmano R, Altieri $P$ et al (1992) Extracellular matrix formation by epithelial cells from human polycystic kidney cysts in culture. Virchows Arch B Cell Pathol Incl Mol Pathol 63, 1-9

12. Lee EL, Song SA, Mun HW et al (2014) Blockage of interleukin-8 receptor signaling inhibits cyst development in vitro, via suppression of cell proliferation in autosomal polycystic kidney disease. Nephrol 19, 471-478

13. Canaud G, Knebelmann B, Harris PC et al (2010) Therapeutic mTOR inhibition in autosomal dominant polycystic kidney disease: what is the appropriate serum level? Am J Transplant 10, 1701-1706

14. Zafar I, Ravichandran K, Belibi FA, Doctor RB and Edelstein CL (2010) Sirolimus attenuates disease progression in an orthologous mouse model of human autosomal dominant polycystic kidney disease. Kidney Int 78, 754-761

15. Wahl PR, Le Hir M, Vogetseder A et al (2007) Mitotic activation of Akt signalling pathway in Han:SPRD rats with polycystic kidney disease. Nephro 12, 357-363

16. Ibraghimov-Beskrovnaya $O$ and Natoli TA (2011) mTOR signaling in polycystic kidney disease. Trends Mol Med 17, 625-633

17. Fukuda R, Hirota K, Fan F et al (2002) Insulin-like growth factor 1 induces hypoxia-inducible factor 1-mediated vascular endothelial growth factor expression, which is dependent on MAP kinase and phosphatidylinositol 3-kinase signaling in colon cancer cells. J Biol Chem 277, 38205-38211

18. Zhong H, Chiles K, Feldser D et al (2000) Modulation of hypoxia-inducible factor 1alpha expression by the epidermal growth factor/phosphatidylinositol 3-kinase/PTEN/ AKT/FRAP pathway in human prostate cancer cells: implications for tumor angiogenesis and therapeutics. Cancer Res 60, 1541-1545

19. Bae WY, Choi JS, Kim JE and Jeong JW (2015) Cinnamic aldehyde suppresses hypoxia-induced angiogenesis via inhibition of hypoxia-inducible factor-1alpha expression during tumor progression. Biochem Pharmacol 98, 41-50

20. Mi C, Ma J, Wang KS et al (2017) Imperatori suppresses proliferation and angiogenesis of human colon cancer cell by targeting HIF- $1 \alpha$ via the mTOR/p70S6K/4E-BP1 and MAPK pathways. J Ethnopharmacol 203, 27-38

21. Kang CB, Hong Y, Dhe-Paganon S and Yoon HS (2008) FKBP family proteins: immunophilins with versatile biological functions. Neurosignals 16, 318-325

22. Harrar Y, Bellini C and Faure JD (2001) FKBPs: at the crossroads of folding and transduction. Trends Plant Sci 6 , 426-431 
23. Pong K and Zaleska MM (2003) Therapeutic implications for immunophilin ligands in the treatment of neurodegenerative diseases. Curr Drug Targets CNS Neurol Disord 2, 349-356

24. Lopez-llasaca M, Schiene C, Kullertz G et al (1998) Effects of FK506-binding protein 12 and FK506 on autophosphorylation of epidermal growth factor receptor. J Biol Chem 273, 9430-9434

25. Costantini LC, Cole D, Chaturvedi P and Isacson O (2001) Immunophilin ligands can prevent progressive dopaminergic degeneration in animal models of Parkinson's disease. Eur J Neurosci 13, 1085-1092

26. Guo X, Dawson VL and Dawson TM (2001) Neuroimmunophilin ligands exert neuroregeneration and neuroprotection in midbrain dopaminergic neurons. Eur J Neurosci 13, 1683-1693

27. Ross DT, Guo H, Howorth $P$ et al (2001) The small molecule FKBP ligand GPI 1046 induces partial striatal re-innervation after intranigral 6-hydroxydopamine lesion in rats. Neurosci Lett 297, 113-116

28. Christner C, Herdegen 'T and Fischer G (2001) FKBP ligands as novel therapeutics for neurological disorders. Mini Rev Med Chem 1, 377-397

29. Avramut $M$ and Achim CL (2002) Immunophilins and their ligands: Insights into survival and growth of human neurons. Physiol Behav 77, 463-468

30. Dunlop EA and Tee AR (2009) Mammalian target of rapamycin complex 1: Signalling inputs, substrates and feedback mechanisms. Cell Signal 21, 827-835

31. Garcia JA and Danielpour D (2008) Mammalian target of rapamycin inhibition as a therapeutic strategy in the management of urologic malignancies. Mol Cancer Ther 7, 1347-1354

32. Long C, Cook LG, Hamilton SL, Wu GY and Mitchell BM (2007) FK506 binding protein 12/12.6 depletion increases endothelial nitric oxide synthase threonine 495 phosphorylation and blood pressure. Hypertension 49, 569-576

33. Raagel H, Saalik P and Pooga M (2010) Peptide-mediated protein delivery-which pathways are penetrable? Biochim Biophy Acta 1798, 2240-2248

34. Liu Y, Wang S, Luo S et al (2016) Intravenous PEP-1GDNF is protective after focal cerebral ischemia in rats. Neurosci Lett 617, 150-155

35. Kim SY, Sohn EJ, Kim DW et al (2011) Transduced PEP-1-K506BP ameliorates atopic dermatitis in NC/Nga mice. J Invest Dermatol 131, 1477-1485

36. Kim DW, Lee SH, Shin MJ et al (2015) PEP-1-FK506BP inhibits alkali burn-induced corneal inflammation on the rat model of corneal alkali injury. BMB Rep 48, 618-623

37. Liu Y, Wang S, Luo S et al (2016) Intravenous PEP-1GDNF is protective after focal cerebral ischemia in rats. Neurosci Lett 617, 150-155
38. Tan LG, Xiao JH, Yu DL et al (2015) PEP-1-SOD1 fusion proteins block cardiac myofibroblast activation and angiotensin II-induced collagen production. BMC Cardiovasc Disord 15, 116

39. Hwang HS, Park IY, Kim DW et al (2015) PEP-1FK506BP12 inhibits matrix metalloproteinase expression in human articular chondrocytes and in a mouse carrageenan-induced arthritis model. BMB Rep 48, 407-412

40. Laplante $M$ and Sabatini DM (2012) mTOR signaling in growth control and disease. Cell 149, 274-293

41. Novalic Z, van der Wal AM, Leonhard WN et al (2012) Dose-dependent effects of sirolimus on mTOR signaling and polycystic kidney disease. J Am Soc Nephrol 23, 842-853

42. Serra AL, Poster D, Kistler AD et al (2010) Sirolimus and kidney growth in autosomal dominant polycystic kidney disease. N Engl J Med 363, 820-829

43. Walz G, Budde K, Mannaa M et al (2010) Everolimus in patients with autosomal dominant polycystic kidney disease. N Engl J Med 363, 830-840

44. Shillingford JM, Piontek KB, Germino GG and Weimbs T (2010) Rapamycin ameliorates PKD resulting from conditional inactivation of Pkd1. J Am Soc Nephrol 21, 489-497

45. Foster DA and Toschi A (2009) Targeting mTOR with rapamycin: one dose does not fit all. Cell Cycle 8, 1026-1029

46. Chang ES, Park EY, Woo YM et al (2015) Restoring multidrug resistance-associated protein 3 attenuates cell proliferation in the polycystic kidney. Am J Physiol Renal Physiol 308, F1004-F1011

47. Okada H, Ban S, Nagao S et al (2000) Progressive renal fibrosis in murine polycystic kidney disease: an immunohistochemical observation. Kidney Int 58, 587-597

48. Ramasubbu K, Gretz N and Bachmann S (1998) Increased epithelial cell proliferation and abnormal extracellular matrix in rat polycystic kidney disease. J Am Soc Nephrol 9, 937-945

49. Rankin CA, Itoh $Y$, Tian $C$ et al (1999) Matrix metalloproteinase-2 in a murine model of infantile-type polycystic kidney disease. J Am Soc Nephrol 10, 210-217

50. Watnick T and Germino GG (2010) mTOR inhibitor in polycystic kidney disease. N Egn J Med 363, 879-881

51. Bradford MA (1976) Rapid and sensitive method for the quantitation of microgram quantities utilizing the principle of protein-dye binding. Anal Biochem 72, 248-254

52. Jo HS, Yeo HJ, Cha HJ et al (2016) Transduced Tat-DJ-1 protein inhibits cytokines-induced pancreatic RINm5F cell death. BMB Rep 49, 297-302

53. Jo HS, Kim DS, Ahn EH et al (2016) Protective effects of Tat-NQO1 against oxidative stress-induced HT-22 cell damage, and ischemic injury in animals. BMB Rep 49, 617-622 